\title{
ROLE OF ONLINE COLLABORATIVE PLATFORM IN HIGHER EDUCATION CONTEXT
}

\author{
Qais Ali Mohammed ${ }^{1^{\star}}$, Vikas Rao Naidu ${ }^{2^{*}}$, Maiya Said Abdullah Al Harthi ${ }^{3}$ \\ Suha Babiker ${ }^{4}$, Qais Al Balushi ${ }^{5}$, Mohammed Yousuf Al Rawahi ${ }^{6}$, \\ Nasiba Harib Saif Al Riyami ${ }^{7}$
}

\author{
${ }^{1} \mathrm{Mr}$, Middle East College, Muscat Oman,13f10559@mec.edu.om \\ ${ }^{2} \mathrm{Mr}$, Middle East College, Muscat Oman, vikas@mec.edu.om \\ ${ }^{3}$ Ms, Middle East College, Muscat Oman, 14f12309@mec.edu.om \\ ${ }^{4}$ Ms, Middle East College, Muscat Oman, 13f10241@mec.edu.om \\ ${ }^{5} \mathrm{Ms}$, Middle East College, Muscat Oman, 15f14856@mec.edu.om \\ ${ }^{6} \mathrm{Ms}$, Middle East College, Muscat Oman, 14f12292@mec.edu.om \\ ${ }^{7} \mathrm{Ms}$, Middle East College, Muscat Oman, 14f12291@mec.edu.om \\ ${ }^{*}$ Corresponding Authors
}

\begin{abstract}
The education sector has already embraced the new generation of technology and started working towards the enhancement of various teaching and learning strategies. With the involvement of various e-tools, teaching and learning process is reaching its next level of implementation. At present, almost every educational establishment is working on implementing various e-resources on their own Virtual Learning Environment. Some of these are even cloud-based and hence enable the end-users (teachers and students), to access the e-resources and collaborate in-class activities even from remote locations. When it comes to group assessments, various collaborative tools come into the picture. Many educational organizations allow their students to access social media platform such as Facebook etc and conduct collaborative exercises on it. One of the critical aspects of enhancing learning through social networks is the fact that distance or off-campus students are limited from meeting with their teachers and addressing them face-to-face. However, both on-campus and off-campus students do have a Facebook account, thus breaking the distance barrier between students and teachers. By using Facebook chat, students can communicate in real-time with each other or with their lecturers. Other such platforms include Microsoft Kaizala, which is becoming popular during these days since it doesn't require the participants to share their private accounts or mobile numbers in order to do an online collaboration for academic purpose. This research paper contains a study of various online collaborative tools, their pros and cons, recommendations for usage and implementation. Finally, the authors will reflect on their studies and suggest various ways of implementations for different purpose and nature of assessments, in order to cover the learning outcomes of the session.
\end{abstract}

Keywords: Smart education, e-resources, online learning, education technology, social media for education

\section{INTRODUCTION}

Throughout the years, social media has risen to be one of the fastest growing sources of information and connection establishment between organizations and people worldwide. Social media is a prominent aspect 
of our lives and it has evolved from a pastime activity to an essential platform that builds careers. The endeavor to intertwine education with social media has already started for the past few years, depending on the social media relevance with the teaching and learning content in improving the educational experience. The higher education sector is allowing the students to bring their smart devices to the campus and many organizations have campus wide internet access in order to enable the usage of various e-learning resources. Based on the nature and content of module / subject, collaborative learning has been identified as one of the most effective teaching and learning methods, especially for group-assessments and activities. Blend of collaborative learning methods with e-learning platform is the really needed these days so that group members could connect even from remote location and contribute to the group activities.

With the advent of Web 2.0 and HTML5 based toolsets, the content authoring for e-learning for various purposes including collaborative learning has become very easy. Implementation of these can be easily done on the Virtual Learning Environment (VLE) by means of various plugin options. (Sharma \& Naidu, 2020) However challenges related to the practical modules are always there where online environment could have certain limitations. For this, the concept of Virtual Laboratories, which are generally planned on cloud could be very effective. This not only reduces the physical laboratory installation costs, but also it provides increased accessibility of lab resources remotely. (Al Ajmi et al., 2017) Latest trends in education technology includes involvement of artificial intelligence, including learning analytics and machine learning has taken the education system to a new dimension. With various methods of prediction, the institutions are now capable of improving their teaching and learning strategies to increase students participation and performances. (Naidu et al., 2020)(Rao Naidu et al., 2017)

\section{LITERATURE REVIEW}

\subsection{Collaborate E-Learning:}

These days, professors and students need to be more digitally connected to their coursework and one another. Fewer in-person interactions can often make students feel disconnected from their learning experience. Sometimes it is hard for the students to be there in person with all the other demands on their time which makes it nearly impossible to attend class. Collaborative e-learning offers a level of connection and engagement that allows professors and students to share their work and ideas which provide a fully wide-ranging learning environment. Collaborative e-learning has been confirmed by many studies to help construct knowledge through group interactions and help develop critical thinking skills such as analysing and evaluating information which is needed for the real world. (Mohammed et al., 2019)

Students will acquire collaboration skills which will develop through effective communication in online environments which will make students reach out to each other to solve problems and share the knowledge that will lead to even deeper learning and understanding of the subject. This study showed that collaborative e-learning is indeed effective especially for the teachers who plan to conduct group-based projects and activities where they can measure individual contribution and the outcome. (Mustafa et al., 2019)

Different teaching methods can be used in different situations when it comes to collaborative learning such as discussion methods, problem-solving, case study or debating. It occurs as the students are actively involved in the process of constructing meaning and knowledge from the course content as opposed to passively receiving the information. Students will be able to exchange some data or ideas where it blends with other students' experience where they can all benefit of others contributing knowledge. (Mohammed et al., 2019)

\subsection{Student Engagement:}

Student engagement represents a wide range of tasks that involves the student's participation and development within management, research, education, and community. It focuses on the interaction between the effort, time, and any resources that involves the investment of together the institution and its students with their reputation and performance. Student engagement in a collaborative manner leads to a collaborated outcome of institutes and their students.

The engagement includes student's involvement in peer support, extracurricular courses, educational provision programs and governance and curriculum development. Not only it induces a culture that authorizes students to be involved but also it induces a formal framework for students' involvement, where the relationship between students and faculties are clearly and explicitly explained. It maximizes the two-way feedback between students and faculties. Diligently engages students in curriculum development and design to have a positive effect on their academic performance that provides development in certain skills such as leadership, teamwork, personal, professional and critical thoughts. (Peters 2018) 


\subsection{E-Learning Environment:}

E-Learning Environment is a main part of the education institutions, since the last decade people have been using e-learning more and more often and there have been studies that show that the environment of elearning is even more healthy and effective for the new generation of students bringing positive results such as: Easy Assessment Tracking, Effective Delivery, Savings on Finance, Flexibility and Time Saving. Countless studies and researches were conducted to influence and capture a student's performance using E-Learning to conclude if the E-learning Environments was positive or otherwise.

With the use of internet and its improvement over the past decade, people have been using the internet on a daily basis, with more and more articles and studies posted online, it is easier for teachers and students alike to find information online easily and it has improved the e-learning environment, the quality of information is precise and the flow of information shows exactly what the students and teachers are looking for, thus making studying easier and more effective. (Dillenbourg, 2007)

One study was conducted to view the results of student engagement and outcomes using e-learning taking in many unique students and colleges into consideration, there were many results varying from engagement and access but all of them had one common results showing an improvement in the results of passing and how the students engage with the material proving that the e-learning environment is the future of education (A.Boulton, 2018).

A different study was also conducted to view the students' performance using E-Learning Environments, taking age, gender and the year of degree respectively, the results were positive showing improvement in the number of students accessing the e-learning environment and students passing the e-learning environment, of course there were a number of students that failed but there was a significant difference between the students that passed and failed (Alves, 2017).

\subsection{Social Media in E-Learning:}

Since the technology is improving, so are ways of teaching and learning. As social networking started taking over people's lives, students from all over the globe are investing an enormous amount of time using social networks. In 2011, it was documented that Facebook was the most used website on the internet, with over 606 million audience (Ryan \& Xenos 2011). Facebook was originated in Harvard University which gave a new look to the used technology such as Emails, with its variation in communication delivery such as writing on walls, and party invitation distributions. This has driven researchers to figure out a way to enhance learning through Facebook-based social networks.

Implementation of collaborative environment for active learning based on Social Media, should be also governed by the country's norms and regulations. It involves various factors governing social, legal and ethical consideration, before we roll out such methodology in teaching and learning. (Al Mamari et al., 2019)

Many studies and researches were conducted to enhance the student outcomes through Facebook to push forward flexible learning. Using Facebook as a learning tool and environment gave a win-win situation to the institutions, allowing them to offer dual-mode courses to both on-campus and off-campus students, by developing online communities that increases the positive outcomes.

One of the critical aspects of enhancing learning through social networks is the fact that distance or offcampus students are limited from meeting with their teachers and addressing them face-to-face. However, both in-campus and off-campus students do have a Facebook account, thus breaking the distance barrier between students and teachers. By using Facebook chat, students can communicate in real time with each other or with their lecturers.

During the past decade there has been a significant change in the communication to the Computer Mediated Communication (CMC) as many users have started accessing and using the web to communicate with each other. Several researches conducted by Barnes, Marateo and Ferris (2007) as well as Oblinger and Hagner (2005), have assured that today's students are easily bored with traditional ways of learning, and that CMC is an essential tool in teaching.

One of the limitations argued by VanDoorn and Eklund (2013) is that to maintain a videoconference, textbased chat, or deliver material, a fast bandwidth connection is required. Moreover, in technologies such as emails and text messages, shortened and informal language can be used which can be inappropriate.

Although Facebook has many uses as mentioned above, the case study is focused more on the synchronous text-based CMC. The text-based communication in Facebook is free of charge regardless of the area or the distance between the users, enabling teachers and students to interact through typed 
messages in real time.

It was conducted through the volunteered students - both day and distance students - who added their lecturer as a "friend" on Facebook through permission, that the instant feedback received from the lecturer using Facebook chat has decreased the time which is usually lost in seeking certain information. Thus, benefiting the final learning outcome. Furthermore, by using CMC to communicate with the lecturer, the distance students that have no access to face-to-face communication with the lecturer had the opportunity to interact in real time with the lecturer and get direct feedback which would not be possible otherwise.

The beneficial points of using text-based communication through Facebook, is that it works directly from the website, without having the need to download and learn any additional software. Moreover, text-based communication is a series of short and simple messages, which does not need a high-speed internet connection to use compared to video conference. Furthermore, the "Faceless" anonymity of text-based communication gives the students an opportunity of asking questions that might not be asked during face-toface communication. However, using the CMC can apply more pressure on the lecturing staff as increasing the workload by having to be online and replying as soon as possible. Another potential issue would be the exposure to commercial enterprises. As it is known that Facebook and other social media platforms are commercial enterprises, the students and the lecturers are exposed to advertisements which are not within the protection of the university. Since CMC is not only limited to Facebook, an option to resolve this issue is to create a platform within the university.

\section{ANALYSIS}

A short questionnaire was distributed among the 50 respondents of one the higher education institutions in Oman, asking about student-engagement as well as their take on collaborative learning, and to check if the use of applications or social media is incorporated into the teaching methods in their classroom. The survey was conducted after obtaining consent of the participants. The following analysis is the result of the questionnaire consisting of 5 questions, distributed among higher diploma and bachelor level students.

\subsection{Question 1: Do you think student engagement in class needs improvement?}
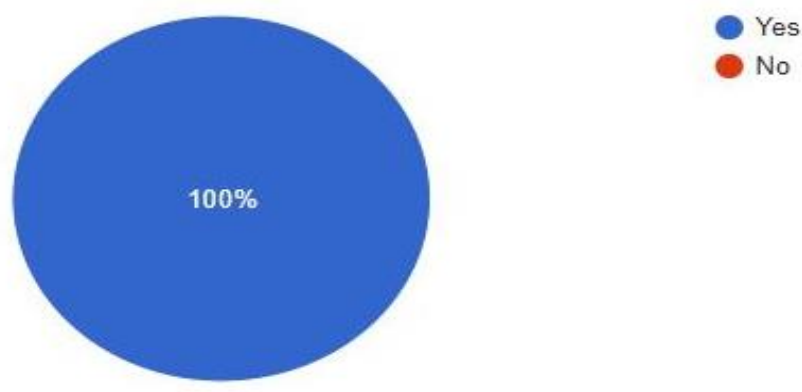

Fig 1. Student Engagement needs improvement

Fig. 1 shows all the students who answered the questionnaire agreed that the student engagement needed improvement or at least a change to better their experience in the classroom.

\subsection{Question 2: Do you think online collaboration between teacher and students enhances student engagement in class?}

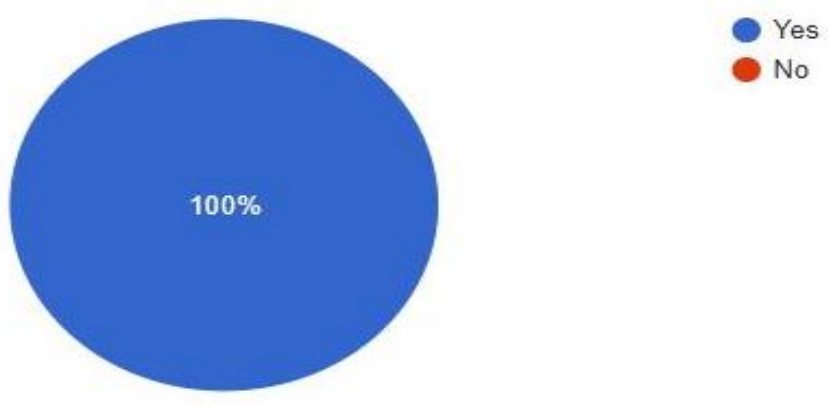

Fig 2. Online collaboration between teacher and students 
This question was asked to learn if the students were willing to engage in an online session using an application or a social media platform with their teacher to enhance the student experience in the classroom. All of the respondents answered with 'yes' in which shows that students are willing to engage in online sessions to enhance their classroom engagement with each other.

\subsection{Question 3: How often are you exposed to collaborative E-learning?}
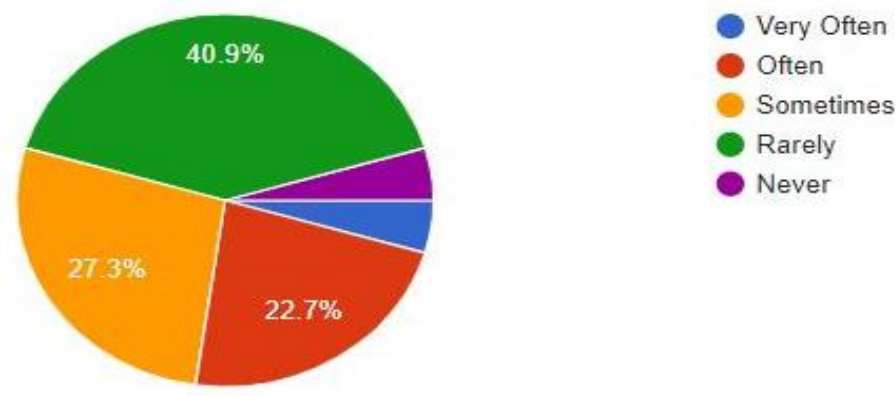

Fig 3. Usage of collaborative e-learning

The third question aimed to observe if respondents have tried or learned about collaborative e-learning in their classrooms. The students answered as follows: $4.5 \%$ answered (very often), $22.7 \%$ answered (often), $27.3 \%$ answered (sometimes), $40.9 \%$ answered (rarely), and $4.5 \%$ answered (never). That indicates that the majority of the students rarely get exposed to collaborative e-learning methods in their classrooms.

\subsection{Question 4: Do you use e-learning applications in the classroom to learn lessons? If yes, can you mention the name of the used application?}
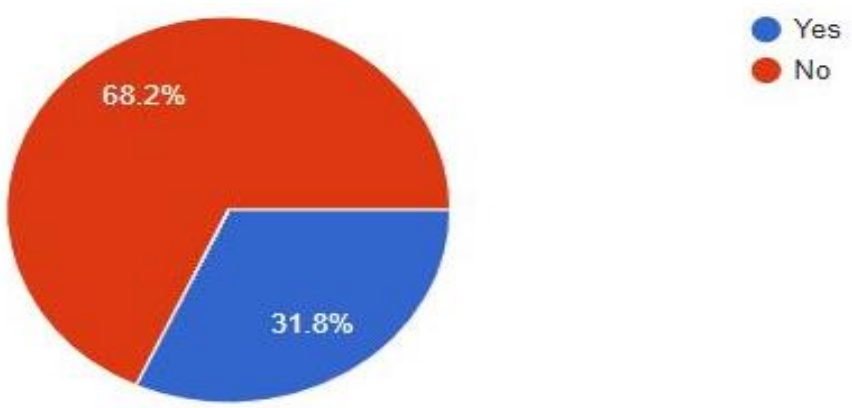

Fig 4. Usage of E-learning applications

The question aimed to find out if respondents are getting educated about using online applications, and to find out which applications they are using in the classroom. 68.2\% answered (No), while $31.8 \%$ answered (Yes), and that indicates that more than half of the respondents do not get taught about using online applications. Furthermore, the respondents that got to learn about using online applications answered the sub-question with "Moodle", and one of the respondents answered with "YouTube for discussion materials mostly". Some respondents mentioned that their teachers used some mobile applications such as Padlet, LiveBoard, and social media apps such as WhatsApp and Microsoft Kaizala.

\subsection{Question 5: How effective do you think collaborative learning methods are in covering the learning objectives in class?}
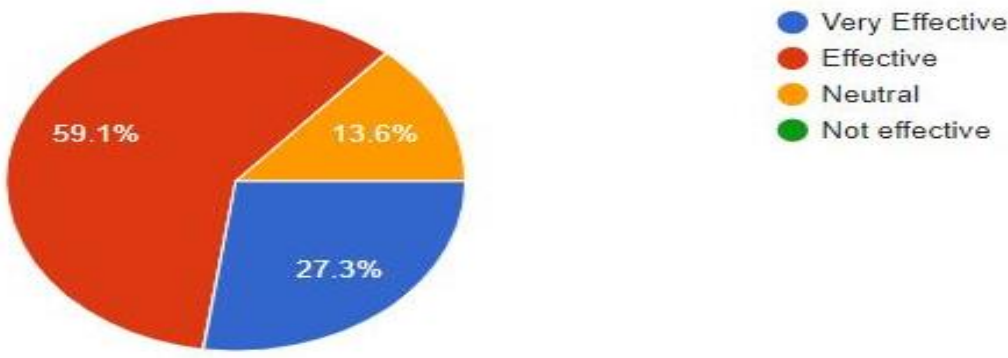

Fig 5. Effectiveness 
The last question was asked to observe the respondents' point of view on covering the learning objectives that are to be achieved in class. Since many respondents have engaged in collaborative learning and they can observe their understanding of the lessons that are being taught to them in the class, $27.3 \%$ answered (very effective), while $59.1 \%$ answered (effective) and $13.6 \%$ answered (neutral). This indicates that most of the respondents find the collaborative learning method of teaching is positively effective in helping them understand their lessons and achieve the learning objectives of the class.

\section{RESULT}

The analysis of all the questionnaire shows that students in general do feel the need to improve the engagement and the experience of the classroom. Furthermore, they are accepting the incorporation of applications and social media to enhance their learning experience, which is found to be much better than the traditional methods of teaching and learning. However, the study has shown that not every subject needs to be taught using online collaborative mode. Because this mode of teaching has its own drawbacks, especially related to monitoring of active participation of the students.

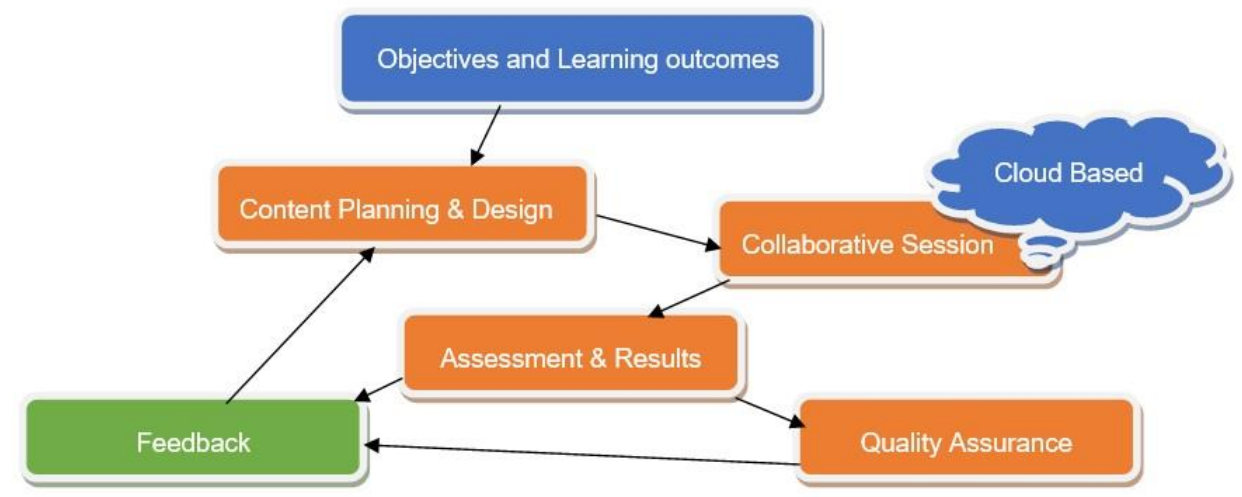

Fig 6. Proposed implementation

As seen in Fig 6, where the authors have proposed a framework for implementation. In the $1^{\text {st }}$ stage, the objectives and learning outcomes of the session needs to be identified. Accordingly, content planning and design is done. The content of collaborative sessions is different from that of regular session. The content of regular session may involve any type of learning materials since the direct supervision of the teacher is possible here. Whereas, in collaborative sessions organized online, the direct supervision is not possible, and hence the content planning should be done in such a way that teachers will have some control mechanism to monitor the progress. For example, if there is implementation of interactive videos using tools such as Edpuzzle, it facilitates an option to provide learning analytics to monitor the students progress through the course along with intermediate assessments in the form of interactive activities such as quiz etc. Conduct of assessment is also planned accordingly followed by feedback. The overall process needs to be monitored by Quality Assurance unit of the institution to ensure the effectiveness and smooth conduct of these activities.

While students are making use of social media from remote places, to participate in study-related activities, it becomes almost impossible for a teacher to monitor if the usage of social media in collaborative study is not being mis-used. Hence, by conducting formative assessments on regular basis, teachers can ensure that students are participating in the class activities. Feedback is important to ensure the effectiveness of this method of teaching. Based on the responses from the students, necessary steps could be taken for future enhancement.

\section{CONCLUSION}

Technology has both positive as well as negative aspects on human life. Especially in education sector, monitoring the usage of technology is important. This research paper has shown very positive results on usage of collaborative e-learning platforms to enhance teaching and learning experience in education sector. But at the same time, the teachers and the network administrator must ensure that the implementation of this method is being monitored and data must be analyzed for future enhancement. There are many chances of getting deviated from the intended class activity and get involved in personal usage of social media during the class sessions. And hence, the collaborative activities must be defined in such a way that all the group members could participate actively with full interest. 


\section{ACKNOWLEDGEMENT}

The authors would like to sincerely thank God almighty whose blessings were there in each stage of successful completion of this collaborative research work. Authors would thank the faculty and management of Middle East College for encouragement in this research. Our sincere thanks to our families who are always encouraging us in new ventures towards our academic success.

\section{REFERENCE LIST}

Al Ajmi, Z., Al Badai, N., \& Naidu, V. R. (2017). VIRTUAL LABORATORIES: THE FUTURE OF ACTIVE LEARNING OF PRACTICAL MODULES IN HIGHER EDUCATION. ICERI2017 Proceedings, 1, 8673-8676. https://doi.org/10.21125/iceri.2017.2365

Al Mamari, R., Naidu, V. R., \& Agarwal, A. (2019). A PROPOSED FRAMEWORK FOR EFFECTIVE USAGE OF SOCIAL MEDIA IN HIGHER EDUCATION ESTABLISHMENTS. EDULEARN19 Proceedings, 1, 73377341. https://doi.org/10.21125/edulearn.2019.1755

Naidu, V. R., Singh, B., Farei, K. Al, \& Suqri, N. Al. (2020). Machine Learning for Flipped Teaching in Higher Education-A Reflection (pp. 129-132). Springer, Cham. https://doi.org/10.1007/978-3-030-32902-0_16

Rao Naidu, V., Singh, B., Hasan, R., \& Al Hadrami, G. (2017). LEARNING ANALYTICS FOR SMART CLASSROOM IN HIGHER EDUCATION. Ocerint International, Istanbul. http://www.ocerint.org/socioint17 epublication/abstracts/papers/432.pdf

Sharma, A., \& Naidu, V. R. (2020). A STUDY ON EMERGING TRENDS TO ENHANCE LEARNING EXPERIENCE IN HIGHER EDUCATION INSTITUTIONS. INTED2020 Proceedings, 1, 7391-7396. https://doi.org/10.21125/inted.2020.1974

Alves, P., Miranda, L. and Morais, C. (2017). The Influence of Virtual Learning Environments in Students' Performance. Universal Journal of Educational Research, 5(3), pp.517-527.

Boulton, C., Kent, C. and Williams, H. (2018). Virtual learning environment engagement and learning outcomes at a 'bricks-and-mortar' university. Computers \& Education, 126, pp.129-142.

Dillenbourg, P., Scheider, D. and Synteta, P. (2019). Virtual Learning Environment. 3rd Hellenic Conference "Information \& Communication Technologies in Education". [online] Available at: https://telearn.archives-ouvertes.fr/hal-00190701 [Accessed 24 Sep. 2019].

ResearchGate. (2019). Twelve tips for enhancing student engagement. [online] Available at: https://www.researchgate.net/publication/324689566_Twelve_tips_for_enhancing_student_engage ment [Accessed 10 Sep. 2019].

Mohammed, Q., Rao, V., Hassan, R., Mustafa, M. and Jesrani, K. (2019). Digital Education Using Free And Open Source Tools To Enhance Collaborative Learning. [online] ljaedu.ocerintjournals.org. Available at: http://ijaedu.ocerintjournals.org/tr/download/article-file/705009 [Accessed 21 Sep. 2019].

Mustafa, M., Rao, V., Mohammed, Q., Jesrani, K., Hasan, R. and Al Hadrami, G. (2019). A Framework For Collaborative And Activelearning For Enhancing Student Engagement. [online] ljaedu.ocerintjournals.org. Available at: http://ijaedu.ocerintjournals.org/en/download/article-file/705026 [Accessed 12 Sep. 2019].

Mustafa, M., Rao, V., Mohammed, Q., Jesrani, K., Hasan, R. and Al Hadrami, G. (2019). A Customized Framework To Enhance Students Engagement In Collaborative Learning Space Inhigher Education. [online]. Available at: https://www.researchgate.net/profile/Raza_Hasan3/publication/331479710_A_Customized_Framewor k_to_Enhance_Students_Engagement_In_Collaborative_Learning_Space_in_Higher_Education/links/ 5c7bd54c92851 c6950509a02/A-Customized-Framework-to-Enhance-Students-Engagement-InCollaborative-Learning-Space-in-Higher-Education.pdf [Accessed 12 Sep. 2019].

Oblinger, D. G. \& Hagner, P. (2005). Seminar on educating the Net Generation. Paper presented at EDUCAUSE. http://www.educause.edu/section_params/conf/esem052/OneDayv2-HO.ppt\#3

VanDoorn, G. and A.Eklund, A. (2013). Face to Facebook: Social media and the learning and teaching potential of symmetrical synchromous communication. 
Barnes, K. Marateo, R. C. \& Ferris, S. P. (2007). Teaching and learning with the Net Generation. Innovate Journal of Online Education, 3(4).

Ryan, T. \& Xenos, S. (2011). Who uses Facebook? An investigation into the relationship between the Big Five, shyness, narcissism, loneliness, and Facebook usage. Computers in Human Behavior. 